\title{
"And an Island Never Cries": Cultural and Societal Perspectives on the Mega Development of Islands in the United Arab Emirates
}

\author{
Pernilla Ouis
}

\section{Why Islands? Islomania in the United Arab Emirates}

This chapter aims at revealing cultural and societal aspects of the megaengineering of artificial islands and other island development projects in the United Arab Emirates (UAE). The UAE is a federation established in 1971 of seven traditional sheikhdoms or emirates, located on the Arabian coast of the Persian Gulf. The largest emirate Abu Dhabi; and also the name of the capital, but perhaps most famous is the city and emirate of Dubai for its many spectacular and extravagant megaprojects. The number and size of these new island projects can be understood by studying the elaborate chapter "Infrastructure" in the latest official United Arab Emirates Yearbook 2009. This chapter recounts for several projects of this kind that will be the starting point for my article and explained below in detail: In Abu Dhabi city the yearbook mentions that the islands named Sowwah, Al Reem, Saadiyat, Yas and Lulu are undergoing reclamation. In Dubai the world's largest artificial archipelago called The World has been finalized and the three large man-made Palm Islands are under construction with one recently being completed. In the coastal areas of the smaller and poorer northern emirates, islands are being developed as well, following the pattern of the larger emirates.

These islands are all under development, and facts regarding them can not be found in literature yet, but rather on the developing companies' homepages. The presentations found on such homepages are often expressed in visions and fantastic models, while most of these islands, at the time of writing this chapter (spring 2010), are nothing more than large construction sites. Only the future can

\footnotetext{
P. Ouis $(\square)$

Faculty of Health and Society, Malmö University, Malmö Sweden

e-mail: Pernilla.ouis@mah.se
} 
tell if all these great projects will be realized as they are planned particularly given the current economic crisis. This chapter builds on secondary literature sources, Internet and my previous research (Ouis 2002a, b, 2007 and forthcoming) rather than conventional ethnographic fieldwork in the UAE. Moreover, the net-encyclopedia Wikipedia has been consulted, not as a reliable source for facts, but rather as identifying certain "rumors" regarding some projects, in cases where information no longer is available from alternative sources on the Internet.

The aim of the chapter is to discuss some forgotten aspects of cultural and societal aspects of such megaprojects (i.e. the artificial islands) from a human ecological view. A human ecologist approaches nature as if there were humans in nature. To state it simply, in human ecology the actions and interactions of humans in nature are included in the study of ecology. Humans are not disregarded as alien "anthropogenic" factors in nature.

With regard to the many island projects in the emirates, it could be correct to say that there is an "islomania" going on the UAE, a concept used to denote a strong affection or obsession with islands. The term was introduced by the writer Lawrence Durrell in his book Reflections on a Marine Venus (1953). Wikipedia, under the entry "islomania", quotes a letter by Durell, in which he writes: "Islomania is a rare affliction of spirit. There are people who find islands somehow irresistible. The mere knowledge that they are in a little world surrounded by sea fills them with an indescribable intoxication." John Gillis (2004) further explores the theme of islomania stating: "Islands evoke a greater range of emotions than any other land form. We project onto them our most intense desires, but they are also the locus of our greatest fears. We feel extraordinary free there, but also trapped. Associated with pleasure, islands also harbor pain, for they are prisons as frequently as escapes or refuges."

The enormous efforts and resources invested in island projects in the UAE can be interpreted as a way to profit on the mystery and lure attached to islands. The country is struggling to transform its economy from fossil fuel export into tourism and finance. Islomania is one strategy to create attractiveness in a rather barren environment, somehow empty both in terms of natural wonders and historical sites. The new islands fulfill many needs in Emirati society: as new urban flagships necessary for economic diversification, as icons of the traditional past, and as concrete islands enabling economic, religious, social and cultural segregation. A flagship denotes spectacular grand buildings or other centers to stimulate urban development and attract investors, tourists and residents on the global market (see for instance Smyth 1994). The boom in islands is also encouraged by a recent change in the law making it possible for foreigner to buy property on freehold ownership, something hitherto forbidden for non-UAE nationals. Furthermore, being a human ecologist I will attempt to touch upon some ecological aspects of these islands, as well as discussing how artificial islands create a nature-map inversion. Furthermore, a new type of traveler is being identified: the Google Earth tourist. Finally, I will discuss these islands from a perspective of dependency. 


\section{Island Projects in Abu Dhabi: The Responsible Sister}

Abu Dhabi is the capital of the United Arab Emirates, but also the name of the largest ( $87 \%$ of the total territory of the country) and wealthiest emirate of the federation. This is the only emirate that truly fulfills the conditions of being a classical oil state, and the whole federation's expenses are mainly financed by Abu Dhabi's oil revenues. This emirate is invoking philanthropy and the tradition of "playing the role of the more responsible sister" (Easterling 2007), perhaps in relation to its more spoilt little sister Dubai. Still, the emirate invests to meet the post-oil era, which is reflected in its new island mega-projects. The development of the Sowwah Island and Al Reem Island in Abu Dhabi will be the core of the new Central Business District of the city. The district will be about 105 hectares of "commercial, residential and retail infrastructure supported by an extensive network of 13 bridges, public transport links and pedestrian facilities" (United Arab Emirates Yearbook 2009) to connect the area to the existing city centre. The development is associated with economic diversification. The chairman of the Sowwah Island's developer Mubadala, a government-owned company, comments:

\footnotetext{
The work of Mubadala as a catalyst for diversification is particularly important. Through partnerships with local and international organizations, Mubadala builds new businesses and in some cases entire new sectors within the economy of the Emirate of Abu Dhabi. These initiatives expand the economic base of the Emirate and in doing so promise to deliver greater stability and sustainability to its economic performance over time. (Message by His Highness Mohamed Bin Zayed Al Nahyan Crown Prince of Abu Dhabi and Chairman of the Board, Mubadala 2010a).
}

Abu Dhabi has a green, environment-friendly profile on the global market (Ouis 2002a). However, the emirate struggles with the paradox of maintaining an ecological image while selling fossil fuels (that are seen as causing the most acute threat to the global environment due to green house gasses), and still trying to develop their economy. Development companies are well aware of the criticism from the environmental perspective regarding these megaprojects, and always try to address ecological issues. The developer's home-page promises that, although the Sowwah Island project will encompass "a diverse mix of attributes that are vital in the world's leading CBDs, including commercial, hotel, retail and residential clusters as well as community facilities, public amenities, parks and open spaces", it is designed as "a sustainable urban environment". The island will promote alternative means of transport, and reduce the use of energy and water due to its innovative architecture and landscape (Mubadala 2010b).

Sowwah Island, just as Al Reem Island, are both natural islands that are being developed. This is rather new in the region and is considered to be more "ecofriendly" than the creation of new artificial islands, which is the course taken by Dubai. Furthermore, it should be noted that Abu Dhabi since 2005 only accept members in the Gulf Cooperation Council (GCC) to own freehold property, while non-GCC members may have an arrangement with 99 year contracts (Easterling 2007). This suits well a more cautious image in dealing with foreign cultural 
influx. Al Reem will be developed for the same use as Sowwah and is marketed to new residents on the homepage in the package of "a city in the city" as so many islands, in addition to the value of islomania:

Consider your dream home come tucked away in a picturesque island; verdant, mysterious and inspiring. Away from the stressful chaos in the city and its life; yet, with every convenience of the metropolitan lifestyle, that integrates work, home and recreation onto one rostrum, freeing up much valuable time for you to spend doing the things you enjoy. (Al Reem Island 2010).

Yet another island in Abu Dhabi, Saadiyat Island, will be developed and integrated with the city's Cultural District, which includes large museums such as Guggenheim Abu Dhabi (GAD) or Abu Dhabi Louvre that surely will become future flagships for the emirate. Abu Dhabi has a reputation of promoting itself as a center of culture and education, and the Saadiyat development plan should be viewed in this perspective. Hence, the island will be "home to one of the most contagious global spatial products of architourism and culture: the Guggenheim organization" (Easterling 2007). GAD will be 25 times larger than Bilbao and will be completed in 2012. It is expected to be "Abu Dhabi's most iconic masterpieces" (Tourism Development and Investment Company (TDIC) 2010a). The island will host 160,000 inhabitants, but will also include some nature reserves as well. The green image of Abu Dhabi is important in the global marketing of Abu Dhabi as previously discussed, as well as a way of preserving the legacy of the politics of the late Sheikh Zayed bin Sultan Al Nahyan, the "father" of modern UAE who ruled Abu Dhabi from 1966, and through federation from 1971 and until his death in 2004. The developer TDIC explains the project's vision: "Occupying $27 \mathrm{~km}^{2}$ the entire project is due for completion by 2020 and is created around an eco-sensitive philosophy with a special low density masterplan" (TDIC 2010b). The island will have pedestrian access as well via a ten-lane highway bridge. It has a budget for more than 22 billion US dollar, and will be completed in 2018. The island will include $19 \mathrm{~km}$ of new beachfront, 29 hotels, 8,000 villas and 38,000 apartments, according to the UAE Yearbook 2009.

The yearbook also mentions the Lulu Island of Abu Dhabi, a man-made reclaimed island completed in 1992, but not opened to the public until 2007, designed mainly for leisure purposes. Emirates News Agency (2007) reported upon the opening of the island that the objective of the 10-km island development was to create a special world of experiences, combining entertainment with the cultural, recreational and leisure elements. Amenities include marinas, gardens, canals, botanical gardens and children water parks, an equestrian riding centre and a variety of resort accommodation.

But still there are more projects of this kind in Abu Dhabi; the Yas Island will be developed. This island is $25 \mathrm{~km}^{2}$ and will create a $32 \mathrm{~km}$ of "new" waterfront and its development will include the creation of three large theme parks: Ferrari World Abu Dhabi, Warner Brothers Theme Park and Yas Island Water Park (UAE Yearbook 2009). The development of the island will include the building of new signature hotels, theme parks as mentioned, marinas, shopping malls and golf 
courses, just as the rest of the island projects. The "extra" on this island will perhaps be its car racing circuits (Yas Marina Circuit 2010). The island is expected to attract permanent residents as well as tourists.

This is a very short description of the Abu Dhabi island projects, but it has to be kept in mind that these projects include a massive infrastructure development of housing, towers, offices, roads, bridges, commercial and touristic sites. And apart from these island projects, other coastal projects are being developed in the country-the islands are just one scene for the megaprojects.

\section{Duabi: The world of Artificiality}

Dubai, the second emirate of the federation, long ago transformed its economy from fossil fuel into tourism. It is famous for its outstanding artificial island projects. The creation of the flagship of Dubai, the first "seven-star hotel" in the world, Burj al-Arab, was preceded with the construction of a large artificial island to build the hotel upon. The island is located $280 \mathrm{~m}$ from the beach and took 3 years to build; the construction of the hotel took 3 years as well. The hotel can only be reached by a gated bridge or helicopter.

Another spectacular coastal development project is Dubai Marina, a canal city in the "Venetian tradition" according to marketing, with a large central waterway that has been excavated from the desert with a length of $3 \mathrm{~km}$. It was completed in 2004 and the area can accommodate more than 120,000 people (Design Build Network 2010). The marina is not an island as such, but is somehow a forerunner for the island projects in respect to architecture and master plan.

Dubai allows all foreigners to own property, a change in law from 1997 (in special areas, but after 2006 in the whole emirate) that probably has fuelled Dubai's boom in individual freehold property on the global market (Easterling 2007). The artificial archipelago The World of 300 islands together forming the shape of the world, was finalized in January 2008 and the building of infrastructure could commence. Each island can be purchased individually and the UAE yearbook 2009 reports that $50 \%$ of the islands have been sold, but it is uncertain if this number holds true after the financial crisis of 2008. The World has attained much international attention and is being promoted by the developing national company Nakheel as: “A journey. A saga. A legend. The World is today's great development epic. An engineering odessy to create an island paradise of sea, sand and sky, a destination has arrived that allows investors to chart their own course and make the world their own." (Nakheel 2010a). The uniqueness, mystic and originality of each island are used in the marketing. The World further described as "the most innovative real estate on Earth", while still "flourishing marine life", according to Nakheel (2010b).

Perhaps the most spectacular of all artificial islands are the Palm trilogy, three islands each in the shape of a palm tree also constructed by Nakheel. The construction of the first island in a $24 / 7$ procedure, Palm Jumeirah began in June 
2001 and was finalized in 2006. The island measures about $5 \mathrm{~km}$ by $5 \mathrm{~km}$ and residents have started to move in. The procedure for creating this kind of artificial islands (just as The World by the way) is to use sand dredged from the bottom of the sea and which is sprayed onto the designated area. Shortly after Palm Jumeirah was finished a new palm island, Palm Jebel Ali, was announced and reclamation work began. This island will be twice the size of Palm Jumeriah and calculated to be able to accommodate 250,000 residents by the year of 2020 according to the UAE Yearbook 2009. The buildings of the island are mainly private residences owned by foreigners in addition to luxury hotels, and the usual facilities for tourists: beaches, bars, clubs, marinas, restaurants, parks, towers etc.

The development of the third island, the largest of them all Palm Deira commenced in October 2004, an island that will have the incredible size of $46.35 \mathrm{~km}^{2}$. However, it is difficult to get exact information regarding the development of this third palm that has just begun. According to Wikipedia, its "first announced design was 8 times larger than the Palm Jumeirah, and 5 times larger than the Palm Jebel Ali, and was intended to house one million people. Originally, the design called for a $14 \mathrm{~km}$ ( 8.7 mile) by $8.5 \mathrm{~km}$ (5.3 mile) island with 41 fronds. Due to a substantial change in depth in the Persian Gulf the farther out the island goes, the island was redesigned in May 2007. The project then became a $12.5 \mathrm{~km}$ (7.76 mile) by $7.5 \mathrm{~km}$ (4.66 mile) island with 18 larger fronds." It should be clarified that this source has been consulted, since the official site of the Palm Triology (by Nakheel) does not provide any information regarding the planned size for Palm Deira.

After the autumn 2008 and the financial crisis, neither the Yearbook 2009 nor Nakheel's homepage is particularly explicit about the Palm Deira plans. The Yearbook expresses rather vaguely that Nakheel announced in December 2008 that some of its development schedule in the Gulf "is expected to slow down". Also the excavation project Arabian Canal, the $75 \mathrm{~km}$ long canal that will link Palm Jumeriah and Palm Jebel Ali, developed by Limitless announced that the company will review its construction schedule for the project. Still, the Yearbook 2009 mentions the new plans by Nakheel: The Universe, a cluster of coral-shaped islands that will emanate from Palm Jumeria to the other Palm Deira. These new islands will according to images found on the Internet be located between The World and Dubai coast. Hence, the whole coastal area will be filled with artificial islands. However, the Yearbook mentioned that the plans for The Universe will take 15-20 years to realize.

Another important urban flagship relating to Dubai's coast is the Hydropolis, a large underwater hotel supposed to become a "10-star hotel". This hotel should have opened already in 2006, but due to technical, ecological and perhaps financial, problems its opening was delayed. The Yearbook 2009 does notably not even mention this megaproject at all and the project seems to be in limbo. Again Wikipedia, under the entry Hydropolis, is one of the few sites giving any information, states that:

Architects working on Hydropolis have had some difficulty selecting a suitable position for the complex, as concerns have been repeatedly raised about the displacement effect of 
building a 260-hectare underwater structure. If their calculations are incorrect, tides and sea levels off the coast of Dubai could be severely affected, rendering vast tracts of coast uninhabitable due to chaotic tides, flooding, unpredictable wave patterns and a high possibility of whale and other sea-mammal beaching.

\section{The Smaller Emirates: The Poorer Cousins from the Countryside}

It is somehow easy to forget that the UAE is a federation of seven independent emirates, since Abu Dhabi and Dubai tend to dominate the whole country. However, the other smaller emirates in the north and east are much more reminiscents of the emirates before the boom in megaprojects. These emirates, Sharjah, Ajman, Umm al-Qaiwan, Ra's al-Khaimah and Fujairah, could be perceived as the poorer cousins from the countryside compared to urban and fashionable Abu Dhabi and Dubai. These poorer emirates are getting help to develop from national finances, and here islands are being developed as well. Al Nujoom Islands are developed in the Sharjah emirate, mentions the Yearbook 2009. This complex of ten islands are to be created by excavating an intricate system of waterways from the coast, rather than creating man-made islands by spraying sand as in Dubai. The Saudi based company Al Hanoo Holding Company is the developing company. The building of infrastructure and residences has just begun on this complex, and the islands will accommodate over 40,000 new residents when finalized.

In the emirate Ra's al-Khaimah a number of artificial islands are underway. Dana Island, designed as a main stem in three parts and ten leaf-shaped islands and Al Marjan Island, five coral-shaped islands, are also designed as multi-use developments, according to the Yearbook 2009. In this emirate the natural Saraya Islands are being developed as well. This project consists of the islands Al-Boum, Al-Marsa, Al-Sahab and Al-Wahat and they runs parallel to Ras Al Khaimah's coastline, creating a natural lagoon between the islands and the mainland (Sayara Ras Al-Khaimah 2010). It seems like these projects are repetitions of the grand touristic projects of Abu Dhabi and Dubai, but on a more moderate scale. However, all these projects, as well as those in Abu Dhabi and Dubai, are all hit by the decline in the economy.

\section{On Cultural Icons: Legitimizing Modernity by Referring to Tradition}

I have in my PhD thesis in Human Ecology from 2002 promoted the idea that legitimization of power in the UAE is dependent on reference to both tradition and modernity (Ouis 2002a). Another way of expressing the same thing is to say that 
the rulers' ambitions towards modernity are sanctioned by re-articulating important references to the past. Important icons from the traditional lifestyle are frequent in the modern emirates. Cultural symbols such as camels, falcons, tents, boats, pearls, coffee pots, palms and other references to the traditional Bedouin heritage and the former pearling and fishing economies are of importance in the modernization process. Throughout the emirates, these national icons are visible, in various flagship developments, as roundabout monuments, in buildings, landscaping and in advertisement. An example of these referents is the Burj al-Arab hotel that is a modern price of architecture, but based upon the shape of sails from a dhow (traditional boat), enabling the space between the sails to create the world's biggest atrium of $180 \mathrm{~m}$ in height. The hotel has almost literally become the ultimate flagship for Dubai; at least it was until the Burj Khalifa opened (see discussion below).

It is easy to speak ironically of the indulgence in "traditions" in this extremely ultra-modern society as found in the emirates, at least on the surface and in respect to technology and infrastructure. Still, traditions are important to Emirati culture and social structure. The "traditional" is somehow perceived as unauthentic by outsiders. The traditions referred to are definitely so-called invented traditionsmodern attempts to establish continuity with a suitable historic past (Hobsbawn 1983). Still, this is not to say that these traditions are not genuine. Rather they are "articulations of tradition in a modern society" (Ouis 2002a). We have to keep in mind MacCannell's (1976) words that the victory of modernity is not the disappearance of the traditional society as such, but rather the ambitions to preserve and conserve it. Therefore, it makes no sense to be ironic over this constructed "folklore" in the United Arab Emirates, that has been criticized by different researchers as "folklure" (Khalaf 1992) or "fakelore" (Brorman Jensen 2007). The phenomenon of invented traditions appears in all societies during modernization processes, but are much easier identified in "The Other". I would however, argue that what is specific in the UAE is that the legitimization of power and the introduction of modernity are dependent on references to traditions, probably because of the tribal social fabric of the emirates and the speed of change.

The palm islands are typical examples of the successful combining of modernity and tradition. The very shape of the islands - as palm fronds-is ingenious in the perspective of creating long beaches, but also as an iconic shape referring to the traditional date palm. This tree has been planted in millions in the emirates, and is the base for the greening processes of the country (Ouis 2002b). Dates have been a prerequisite for survival in this harsh environment, and the very social structure in traditional Emirati society had the organization of the date farming at its core. The cover of the 1996 official UAE Yearbook 1996, at the official 25 anniversary of the birth of the nation, was the date palms' abundant greenery photographed from above, thus making the date palm perhaps the most important cultural icon in the UAE. On the official Palm Trilogy site it is said that the shape of the palm was chosen to solve the problem of Dubai's beach shortage: "The Ruler of Dubai drew a sketch of a palm tree, realising its fronds would provide more beach frontage than a 
traditional circular island. From this insight, the idea of Palm Jumeirah was born and the trilogy of islands envisioned." (Nakheel 2010c).

The statement above is interesting, since it attributes the genius shape to the ruler Sheikh Mohammed bin Rashid Al Maktoum. The idea of a palm shaped island is both rational, and hence modern, in the same time as it is a reference to the traditional. However, another source states that it was Warren Pickering, an architect based in Australia that came up with the palm idea to solve the beach shortage in Dubai, not Sheikh Mohammed (Elsheshtawy 2004). In official discourse it is however always the ruler that is portrayed as being personally responsible for the articulation of traditional values and symbols. By referring to tradition, the ruler's position is secured.

Yet another arrangement referring to tradition and the legitimization of power of Dubai ruling sheikh, also only viewed from air, are the planned housing typologies on Palm Jebel Ali forming a poem by the same ruler of Dubai. The translation of the poem in English goes:

Take wisdom only from the wise, Not everyone who rides a horse is a jockey. It takes a man of vision to write on water, Great men rise to great challenges. (Translation at Eikongraphia 2010a)

It is an obvious interpretation of the poem that this is a eulogy to himself, however, what most outsiders do not understand is the importance of poetry for the sheikh's secure position and leadership. On his personal homepage his role as a poet is presented as an important aspect of his persona. His poetry is defined as classical Nabati poetry. It is explained as: "Nabati poetry shows the natural creativity of the Gulf's inhabitants and represents their roots in this land. Its form and content, literary significance, social function and historical value make it one of the Arabian Peninsula's great literary treasures" (Sheikh Mohammed 2010). To underline his genuine talent for poetry it is explained that his first published poetry, was published under pseudonym as he wanted to secure that he was not published only because he belonged to the ruling family. His talent in poetry is an asset evoking feelings of authenticity, rather than the artificiality Dubai is famous for embracing.

The tallest building in the world, Burj Khalifa (referred to as Burj Dubai during the building process), is also relating to the traditional and specific, by resembling a desert flower, with the tower's wings extend from a central core. On the tower's homepage it is stated: "No stranger to Middle Eastern design, architect Adrian Smith incorporated patterns from traditional Islamic architecture. But his most inspiring muse was a regional desert flower, the Hymenocallis, whose harmonious structure is one of the organizing principles of the tower's design." (Emaar 2010).

The example of Burj Khalifa reveals another interesting feature of these urban flagships: their vulnerability in addition to the competition between rulers of the different emirates. This tower - the tallest building in the world - that was formerly known as Burj Dubai, was supposed to become the pride of Dubai. However, the financial crisis hit Dubai severely, and it had to turn to Abu Dhabi for financial rescue. In return, it had to rename the tower after the ruler of 
Abu Dhabi (and, it should be noted, the president of the UAE) Sheikh Khalifa bin Zayed bin Sultan al-Nahyan. The price tag for this move is said to be $\$ 1.5$ billion (Tomlinson and Robertson 2010). They report from the top of the tower at the opening ceremony after the "humiliating" re-naming of the tower: "Emerging near the summit after an ear-popping lift ride to its 124th floor, one is reminded of how far Dubai has to go, seeing how much of the city remains incomplete." The traditional sheikdom's power and their long historical internal competition within the federation is actually manifested in the many and large megaproject such as in the various islands project within the country. The UAE as a whole exposes an over-capacity in international airports, hotels, shopping malls, flagships-you name it-due to its traditional competitive ruling structure, and one may add, the lack of central planning.

\section{Hybrid Urbanism: Islands of Segregation}

The word "hybrid" is often used to describe urban development in the UAE. Katodrytis defines Dubai in terms of hybrid urbanism, a term referring to identity discourses articulated in architecture and the built environment (AlSayyad 2001). Katodrytis (2007) describes the city to be everywhere and nowhere, a park-oriented cityscape, a city with no core but consisting of mind-zone spaces, where everything "seems to point to the twin towers of consumerism and tourism". Elsheshtawy (2004) problematizes the view of Dubai as a place of hybrid culture. He says that the official image propagated is that of a happy merging of cultures, while the reality is quite different. In the UAE each cultural, religious and/or ethnic group can create and maintain its set of institutions; they are even requested to do so. The Emirati society organizes differences by segregation.

My observation in the UAE is that it is an extremely segregated society, divided into isolated symbolic "islands" according to ethnic, cultural, economic, religious or other social belongings, opposed to all kind of hybrid ideals. Perhaps most segregated from the rest of society, is the large population of immigrant labour. Elsheshtawy (2004) discusses how no effort is made to resolve social problems in the UAE or to address problems of the immigrant workers or even to improve their conditions.

Marx believed that we have to demystify the social relations behind the consumer goods (i.e. to reveal the exploitation of the labour class), and I think it is necessary to identify the input of labour behind the islands. Basar et al. (2007) notes ironically that literature on Dubai are either "neo-liberal coffee-table glossdross or neo-left moralizing". With the risk of being associated to the neo-left, I think it is important to understand the associated injustices towards the majority of the population: the non-citizen, low-paid, low-skilled working class living in secluded areas. It is crucial to emphasize that the grand and fabulous megaprojects such as these artificial islands are dependent on the non-stop 24/7 labour of the guest workers, work performed under what most societies would consider 
unacceptable conditions. However, what they create with their work are places they will never have access to once these islands are finalized.

The islands themselves, once finalized, are example of Emirati socio-culturaleconomic segregation. Who are they for? It is definitely not for the majority of the people already living in the emirates, not even the middle-class; instead the ultrarich global elite is the target group for such constructs. Planners are expecting hundreds of thousands of this clientele to move to the UAE after the foreign freehold property boom. One may wonder if these plans and astronomical numbers of residents are realistic, but what characterizes these new environments? These islands are utopias, imaginary spaces, dreamscapes or fantasy enclaves, but above all they are colonial spaces, according to Jackson and della Dora (2009). They comment:

Fantasy and luxury spaces — as the Dubai and post-Dubai islands are often deemed to benormalise continuities of structural imbalances in the same way as do perceived 'failures' of urban space (slums, ruins, wastelands, exhausted spaces, etc.). Fantasies and failures together constitute the middle ground of so-called normal expectations of contemporary commodity-driven urban dwelling. Fantasy constructs the imaginary utopic lure as a commodity. Failure constructs the space to be overcome through technical mediation and consumption. (ibid).

As colonial spaces, the new islands have become gated communities for the global and local elite. Elsheshtawy (2004) comments regarding the Palm islands: "Their exclusive nature is further highlighted by locating them offshore, and controlling access through a variety of means: security guards, entrance fees, and by their sheer extravagance, prohibiting (or inhibiting) ordinary folk from entering." Brorman Jensen (2007) argues along similar lines saying that the Palm islands as gated communities opposes the idea of utopian spaces as the "antithesis of exclusion", saying: "The Palm has therefore become an inverse utopia and nothing less than an inversion of the Enlightenment's leitmotif." Social interaction in the Emirati society is built on the dichotomy exclusion and inclusion. It is very clear to each individual living there, with whom one can socialize and in which environment. For instance, Yas Island is presented to future residents:

An island of dreams is taking shape, and for some this will be the home of their dreams. The Yas Island project is all about balance. Balance between thrills and relaxation, man and nature, leisure and residential environments. Across the island there will be a variety of modern low-rise and mixed-use residential areas nestled within landscaped public gardens and alongside parks that incorporate walking/jogging tracks and sporting fields. Imagine taking in the panoramic view of the island of dreams everyday from your luxurious living space. (Aldar 2010).

In reviewing many sites selling these new residents of islands, I have become aware that one often repeated marketing slogan for many of these islands is that the island will constitute "a city within the city". This alludes to the isolation of islands, and thus segregation. The statement by Gillis quoted in the introduction of this article speaks of islands as places where one can feel both free and trapped. The lure and attraction of the Emirati islands on the global market must surely be 
less if they can be perceived as segregated and guarded containers for the elite, almost like prisons.

The islands' closure towards the poorer majority of the population is a strategic closure against traditional and Islamic norms prevalent in the rest of the UAE. The islands will offer an escape for the local elite if they wish to challenge the Islamic morality, while physically still remain within their own country. Judging from the advertisement of the islands, it is Western norms and standards that will prevail in these environments. On the other hand, these islands can welcome Westerners to the UAE without a need for the UAE to liberalize the Emirati society. The islands provide a "free zone within" both for Westerners as well as the Emirati citizens for living according to liberal moral codes with for example access to alcohol. It is almost a paradisian space presented in the marketing of these islands:

\footnotetext{
Visitors will come to enjoy the magnificent sunsets, unwind in the spas, pools and gardens and eat out at the fine selection of restaurants. There's a wide range of daytime activities, including water sports, aquariums, theme parks and of course miles of beautiful beaches. And at night the bars, clubs and shows will offer plenty of fun and amusement. So why not come and explore the endless possibilities Palm Jumeirah has to offer you. (Nakheel 2010d).
}

However, my claim that the island is an escape from Islamic moral codes, should be clarified. It is perhaps only a possibility for national Muslim men to escape the religious norms, since it is totally unacceptable socially for Emirati women to visit night clubs and bars or to swim (i.e. undress and take off their traditional, completely covering, black clothes, although some may use the so-called burkini or have access to gender segregated swimming pools). In all respects of segregation be it based on gender, religion, culture, ethnicity or economic status, it is easy to agree with Elsheshtawy (2004) conclusion that the effect of globalization is segregation in respect to the development in the UAE:

Globalization has thus become another form of domination-primarily catering to those who have the necessary resources. While the imagery associated with the production of spatial forms is linked to cultural elements-an essential post-modern condition-thus suggesting hybridity, it ultimately caters to elite elements, thereby excluding ordinary citizens. Unfortunately, hybridity becomes a 'conspiratorial' actor by concealing its real intentions, cloaking itself in the mantle of tradition and (manufactured) heritage.

\section{Artificial Islands: The Nature/Map Inversion}

Mapping is a human activity in the encounter with nature. However, in relation to artificial islands, "this alliance has been turned upside down", notices Brorman Jensen (2007). The map — the human drawing — becomes nature, and the only limit for nature is the human fantasy. The Palm trilogy is considered to be the 8th wonder in the world, "a miracle that is singled out precisely by being something 
that cannot be imagined". In the press material for the island it is said to be "beyond even nature's vivid imagination" (ibid). Man has thus become the creator of nature. This fact has perhaps inspired Erandi de Silva to elaborate on a "logopelago" of islands in the shape of famous brands such as Disney-Isle-Land (in the shape of Mickey Mouse), Nike's Swoosh symbol, Ralph Lauren Polo Island or why not a Calvin Klein logo Island? (Basar 2004). The island is the symbol, the logo is represented with a particular exclusive lifestyle on the island itself. It is commented: "With projects such as The Palm and The World, Dubai has resuscitated the desire for one-liner icons that speak directly to the sky." (ibid).

Jackson and della Dora (2009) argue that the islands are constructed with the purpose to be recognized by their very artificiality, while they are also built to be invisible from the ground or sea level. They are built to been seen only by a "Godlike viewer" such as a millionaire from his helicopter, or from the Burj al-Arab or Burj Khalifa or by the tourist flying into UAE by air. The islands as icons can also be viewed by the "global population of Google Earth armchair travellers" (ibid). The authors suggest a new Google Earth urbanism. I would say the islands open up for a kind of Google Earth tourism between fantasy and reality. I am strengthened in the view that the islands are more important as icons than real built environment, since most islands are not completed yet and may never be. At the moment, most islands are only visions and models on the developers' homepages or constructions sites which contours and forms are only vaguely seen by Google Earth. Still, they are powerful cultural icons and the fact that they are not yet realized seems to be less important than their power to allude to fantasy and the imaginary. However, the interpretation of those symbols is of course dependent of the context of the observer. For instance, one armchair tourist viewing the palm islands interprets the common phallus symbol in their shape:

The iconography of the islands is not a direct copy of the image of the palm tree, but a more abstract representation of it and therefore leaves room for alternative readings. I tend to see in it also an ejaculating penis, although that reading is perhaps a bit perverse and simplistic. (Eikongraphia 2010b).

I previously stated that "the only limit for nature is the human fantasy". However, as a human ecologist, I do not really believe in that. Human experiences throughout history reveal that nature seems to have the "last word" in what we really can do towards nature. So how is the environment affected by the construction of artificial islands and the exploration of the already existing ones in the UAE? One environmental problem reported is the disruption of tidal flows of nutrients from the deeper parts of the ocean to the shallower coastal areas. All the developers present ecological concerns on their homepages, as mentioned earlier. For instance, the developers of The World, one of the few projects finalized and thus possible to be environmentally evaluated, claim on their homepage:

\footnotetext{
Various sea life, such as coral anemones and sea squirts, thrive along and in between the breakwaters surrounding the islands, accepting it as part of their natural environment. The shoreline areas comprise diverse marine life such as sea cucumbers, oysters, sponges, plankton, butterfly fish and jellyfish. Marine life in and around The World is flourishing.
} 
Initiatives, such as the water treatment plan to reuse water and recycle waste, or the incentives provided for 'Green' developers, will aid in the continued harmony of The World, its customers and its environment. (Nakheel 2010e).

Reading such statements, one can even get the impression that artificial islands are good for the environment. I have in previous publications argued that the discourse of ecological modernization mystifies the true environmental conditions in the UAE (Ouis 2005, forthcoming). The conflict between exploitation and economic development versus the environment is concealed in this discourse, since it is argued that economic growth is a prerequisite for taking care of nature, not a cause for its destruction. Critics have argued that this new environmental discourse celebrating "sustainable development", protects the sustainability of economic development, rather than protecting nature. This attitude is seen in the green marketing of the islands. For instance, the development of Saadiyat Island off Abu Dhabi coast will include a nature reserve, but also a golf course. On the homepage this combination is not problematized as potential conflicting interests: "Home to flourishing natural wetlands, lush mangroves, free-flowing waterways, and the region's first ever tidal golf course. An unforgettable place where man and environment become one." (TDIC 2010c) The developers promise that they have "worked closely with trusted scientific partners in order to ensure that their development do not impinge upon the surrounding environment" and that not a single mangrove plant has been removed. (TDIC 2010d).

But perhaps the most ironic ecological consequences for these islands are the green house effect and the expected climate change and rise of sea water level. The petro dollar is ultimately the explanation of how these islands could be created in the first place, while the very same consumption of fossil fuels may cause the islands' destruction. The future sinking of the Maldives Islands is feared as a result of climate change, and such sinking rumors have hit the newly finalized archipelago The World, but for other reasons. Such speculations are strongly dismissed as false, since the developers argue that the technique of vibro-compaction make the islands having twice the load-bearing capacity of that of mainland Dubai (UAE Interact 2010). However, constructors of artificial islands have considered even the eventuality of sinking islands. New megaprojects with floating islands are being planned, a floating "eco-polis" rescuing peoples' homes from rising sea levels (Jackson and della Dora 2009).

Even if the islands are not threatening the local flora and fauna, neither that the islands will sink nor be affected by climate change, the most severe environmental problem still is not addressed at all in the discussions of the islands: the environmental problem related to lifestyle and consumption issues. This is a part of the mystification of true environmental problems in the discourse of ecological modernization. However, it is a well-known fact that it is the rich countries with high levels of consumption of energy, water and consumer goods, not the poor countries that are depleting the world's resources and affecting ecosystem services negatively, despite the fact that the former, richer countries have access to environmental up-to-date techniques. Hundreds, perhaps millions, new residents will 
come to this extremely sensitive Emirati environment, and they will require water, energy and consumer goods in abundance to sustain their elite lifestyle. For instance, the production of fresh water in the emirates is a very energy consuming and delicate issue, since the UAE locally has very little natural fresh water or ground water left to exploit. Water is produced by desalination of sea water. Local agricultural production in the emirates is also complicated, and many kinds of food stuff must be imported.

\section{Issues of Dependency: No Island is an Island}

The bard John Donne (1572-1631) has written: "No man is an island, entire of itself, every man is a piece of the continent, a part of the main". These influential stanzas, popularized in a protest song in the 1960s, have often been quoted to point out that humans are social beings, dependent on each other. The ethnologist Saltzman (2001) alludes to this poem in her study about a Swedish island. A translation of the Swedish title of her book into English would be "No landscape is an island". She argues that no landscape, not even the landscape of the island she studies, is an island-meaning an independent isolation-in space or time, or free from social issues (Saltzman 2001). Every landscape is interconnected in a web of social and environmental relations. This leads me to the conclusion in regard to the Emirati islands, paraphrasing Donne: No island is an island.

In this chapter I have shown a number of dependency relations that constitute the islands. The construction of these islands are utterly dependent on the sales of fossil fuels in exchange for cheap labour that can materialize these megaengineering projects. Following the dependency school of economic thought (see Frank 1966), exporters of natural resources are always in a dependent relation to the metropolis producing consumer goods. I think this vulnerability still holds true. Even though the demand for fossil fuels is still high, the global shift in energy sources that is slowly taking place due to climate change, will ultimately lessen the demand for fossil fuels. The leadership in the UAE is well aware of this fact, and tries to diversify its economy towards tourism, finance and consumerism. Here is the role for the islands, as explained earlier.

However, I think it is important to pose the question if these elite residents can exist in a post-oil era? Is it really possible to run business as usual? Will not sustainability issues and other ecological concerns put an end to consumerist, luxury lifestyles? Will it, for instance, be possible for millions of tourists to travel by air in a presumed post-oil future? Can nature provide for all these residents? Even if nature "manages" the loads of millions of tourists, the economy of these islands' complexes are still vulnerable to global finance, as experienced in the 2008 crisis. Hence, can these islands be sustainable from an economic or ecological point of view? No island is an island, means that these islands are dependent of different ecological, economic and social relations. They are interwoven in a complex web of relations beyond their control. Such dependent 
relations can pose threats to the sustainability of the islands, or even the chances that they ever be finalized, if the state of the world changes. And the only thing that is constant, is change. Let us hope for the sustainability and stability for these islands projects by wishing that the lines in another song, this time by Simon and Garfunkel, holds true: "I am a rock, I am an island. And a rock feels no pain; And an island never cries."

\section{References}

Aldar (2010) http://www.yasisland.ae/Residences_en_gb.html. Accessed 24 March 2010

Al Reem Island (2010) http://www.reemisland.com/. Accessed 10 March 2010

AlSayyad N (ed) (2001) Hybrid urbanism: on the identity discourse and the built environment. Greenwood Press, Westport

Basar S (2007) Logopelago: Erandi de Silva's ultra luxury lifestyle islands. In: Basar S, Carver A, Miessen M (eds) With/without: spatial products, practices \& politics in the middle east. Bidoun \& Moutamarat, Dubai, pp 144-152

Basar S, Carver A, Miessen M (eds) (2007) With/without: spatial products, practices \& politics in the middle east. Bidoun \& Moutamarat, Dubai

Brorman Jensen B (2007) Dubai: dynamics of bingo urbanism. The Architectural Publisher, Copenhagen

Design Build Network (2010) http://www.designbuild-network.com/projects/dubai-marina/. Accessed 16 March 2010

Durrell L (1953) Reflections on a marine venus: a companion to the landscape of rhodes. Faber \& Faber, London

Easterling K (2007) Abu Dhabi: Extrastatecraft. In: Re_Urbanism: Transforming Capitals, Agrawal K et al. (ed) Perspecta 39: The Yale Architectual Journal, MIT Press, pp 4-16

Eikongraphia (2010a) http://www.eikongraphia.com/?p=223. Accessed 19 March 2010

Eikongraphia (2010b) http://www.eikongraphia.com/?p=217. Accessed 19 March 2010

Elsheshtawy Y (2004) Redrawing boundaries: Dubai, an emerging global city. In: Elsheshtawy Y (ed) Planning middle eastern cities: an urban kaleidoscope in a globalizing world. Routledge, New York, pp 169-199

Emaar (2010) http://www.burjkhalifa.ae/language/en-us/the-tower/design.aspx. Accessed 19 March 2010

Emirates News Agency (2007) Lulu island opens for public, http://www.uaeinteract. com/docs/Lulu_Island_opens_for_public/24757.htm. Accessed 16 March 2010

Frank AG (1966) The development of underdevelopment. Monthly Review, September 1966, pp $17-31$

Gillis J (2004) Islands of the mind: how the human imagination created the atlantic world. Palgrave Macmillan, New York

Hobsbawn E (1983) Introduction: inventing traditions. In: Hobsbawn E, Ranger T (eds) The invention of tradition. Cambridge University Press, Cambridge, pp 1-14

Jackson M, della Dora V (2009) Dreams so big only the sea can hold them: man-made islands as anxious spaces, cultural icons, and travelling visions. Environ Plann A 41:2086-2104

Katodrytis G (2007) Metropolitan Dubai and the rise of architectural fantasy. In: Basar S, Carver A, Miessen M (eds) With/without: spatial products, practices \& politics in the middle east. Bidoun \& Moutamarat, Dubai, pp 244-249

Khalaf S (1992) Gulf socities and the image of unlimited good. Dialect Anthropol 17:53-84

MacCannell D (1976) The tourist: a new theory of the leisure class. Schocken Books, New York 
Mubadala (2010a) http://www.mubadala.ae/en/category/about-mubadala/chairmans-message/. Accessed 10 March 2010

Mubadala (2010b) http://www.mubadala.ae/en/about-mubadala/investments/sowwah-island-project. html. Accessed 10 March 2010

Nakheel (2010a) http://www.theworld.ae/au_overview.html. Accessed 16 March 2010

Nakheel (2010b) http://www.theworld.ae/. Accessed 16 March 2010

Nakheel (2010c) http://www.thepalm.ae/vision.html. Accessed 16 March 2010

Nakheel (2010d) http://www.palmjumeirah.ae/about-palm-jumeirah.php. Accessed 24 March 2010

Nakheel (2010e) http://www.theworld.ae/ev_takingcare.html. Accessed 25 March 2010

Ouis P (2002a) Power, person, and place: tradition, modernity, and environment in the United Arab Emirates. Lund: Lund Studies in Human Ecology no 4

Ouis P (2002b) Greening the emirates: the modern construction of nature in the United Arab Emirates. Cultural Geographies 9(3):334-347

Ouis P (2007) Miljövänliga arabemiraten: Hur världens största resursförbrukare kan upprätthålla en miljövänlig image. Babylon: Tidskrift om Midtösten og Nord-Afrika 5(2):90-99

Ouis P (2010) Engineering the emirates: the evolution of a new environment. In: Brunn SD (ed) Engineering earth: the impacts of megaengineering projects. Kluwer (under publication)

Saltzman K (2001) Inget landskap är en ö: Dialektik och praktik i öländska landskap. Nordic Academic Press, Malmö

Sayara RA (2010) http://www.sarayarak.com/\#1. Accessed 29 March 2010

Sheikh M (2010) http://www.sheikhmohammed.co.ae/vgn-ext-templating/v/index.jsp? vgnextoid=6d1d5c1090cc4110VgnVCM1000007064 a8c0RCRD. Accessed 22 March 2010

Smyth H (1994) Marketing the city: the role of flagship developments in the urban regeneration. E \& FN Spon, London

Tomlinson H, Robertson D (2010) Burj Dubai becomes Burj Khalifa as Emirate loses out on crowning glory, Times on-line, published January 5, 2010, http://www.timesonline.co.uk/tol/ news/world/middle_east/article6976011.ece. Accessed 22 March 2010

Tourism Development and Investment Company (TDIC) (2010a) http://www.saadiyat.ae/en/ Content/About_Our_Partners.aspx. Accessed 16 March 2010

Tourism Development and Investment Company (TDIC) (2010b) http://www.tdic.ae/Projects/ Saadiyat_Island/Overview.aspx. Accessed 16 March 2010

Tourism Development and Investment Company (TDIC) (2010c) http://www.saadiyat.ae/ en/reserve/. Accessed 25 March 2010

Tourism Development and Investment Company (TDIC) (2010d) http://www.saadiyat.ae/en/ Content/reserve/Overview.aspx. Accessed 25 March 2010

UAE Interact (2010) http://www.uaeinteract.com/docs/The_World_islands_not_sinking Nakheel/39491.htm. Accessed 30 March 2010

Vine P (ed) (2009) United Arab Emirates Yearbook 2009. Trident Press, London. http://www.uaeinteract.com/uaeint_misc/pdf_2009/

Wikipedia: Entry: Hydropolis (2010) http://en.wikipedia.org/wiki/Hydropolis. Accessed 29 March 2010

Wikipedia: Entry: Islomania (2010) http://en.wikipedia.org/wiki/Islomania. Accessed 31 March 2010

Wikipedia: Entry: Palm Islands (2010) http://en.wikipedia.org/wiki/Palm_Islands. Accessed 19 March 2010

Yas Marina Circuit (2010) http://www.yasmarinacircuit.ae/. Accessed 16 March 2010 